\title{
Prenatal Nutrition and Fetal Macrosomia in Medically Underserved Areas
}

\author{
Ute Inegbenebor ${ }^{1, *}$ and Maureen Ebomoyi ${ }^{2}$ \\ ${ }^{1}$ Department of Physiology, College of Medicine, Ambrose Alli University, Ekpoma, Nigeria \\ ${ }^{2}$ Department of Physiology, School of Basic Medical Sciences, College of Medical Sciences, University of \\ Benin, Benin City, Nigeria
}

\begin{abstract}
Though fetal Macrosomia is often defined as a condition in which the fetus is 4000 grams or more in weight, controversy exists on the exact birth weight that can be used as a bench mark. Fetal macrosomia creates several diagnostic and management difficulties in developed countries. The difficulties experienced by birth attendants in medically underserved areas in developing countries are probably much more. The development of fetal macrosomia is therefore preferably prevented. This article draws attention to nutritional habits in Nigeria that are capable of escalating the prevalence of fetal macrosomia in areas that are least equipped to deal the associated complications. Nutritionally dependent prevention strategies that could reduce the incidence of fetal macrosomia in medically underserved areas are suggested.
\end{abstract}

Keywords: Prenatal, nutrition, fetal macrosomia, medically underserved areas.

\section{INTRODUCTION}

Though Macrosomia is defined as a fetus or infant that weighs above 4000 grams regardless of age, it is more appropriately defined as fetal weight above the $90^{\text {th }}$ percentile for a given gestational age in weeks [1]. When extrapolated to 40 weeks of gestational age, the result is a birth weight of 4060 grams [2]. However, there is controversy on the use of birth weight of 4000 grams or 4500 grams as a bench mark for fetal macrosomia [2, 3, 15]. Birth weight of 4500 grams may seem more realistic as morbidity sharply increases in United States of America after this birth weight [1]. The fetal birth weight that determines the probability of morbidity may be related to the size and shape of pelvis, which is related to the quality and quantity of nutrition available to a developing girl child. In an analysis of pelvimetry by radiology in 640 cases of primigravidans between 1934 and 1943, It was shown that that the length of the conjugate diameter of the female pelvis is very sensitive to nutrition [4]. Therefore, pelves of well nourished and optimally developed women in countries with well developed economies and would be expected to accommodate larger babies than those of stunted, ignorant and poorly nourished women in poverty stricken and sometimes war torn developing countries.

Macrosomia variously described as large for gestational age or big baby syndrome occurs all over the world in affluent and poverty stricken countries [5].

*Address corresponding to this author at the Department of Physiology, College of Medicine, Ambrose Alli University, Ekpoma, Nigeria;

E-mail: druteinegbenebor@yahoo.com
However, the pregnancy outcome often indicates the stark realities of the difficulties faced by women living in medically underserved areas. In an analysis of 6376 singleton births in Lagos, Nigeria, the prevalence of macrosomia was $4.9 \%$ and the attending perinatal mortality was 58 per 1000 compared to 18 per 1000 in controls [6].

The commonest cause of fetal macrosomia is uncontrolled diabetes mellitus [7]. However, other causes include maternal obesity and excessive gestational weight gain [8]. Excessive gestational weight gain is indicated when it is more than $0.75 \mathrm{Kg}$ per week [9]. It may be due to maternal over-nutrition and/or water retention [8].

The proportion of women who are either overweight or obese is believed to be higher in the developed world due to over-nutrition secondary to affluence. It is relatively difficult to imagine that glucose tolerant persons in the low socioeconomic groups, who may be living on less than one dollar a day, can become overweight. Changing nutritional habits, loss of traditional diets and diminishing physical activity resulting from increasing vehicular transport and sedentary lifestyle in the developing world may reduce this disparity [10]. This article attempts to review fetal macrosomia in relation to nutritional habits in low income communities, and highlight management difficulties faced by skilled birth attendants, in medically underserved areas.

\section{PATHOGENESIS OF FETAL MACROSOMIA}

The placenta controls fetal growth through delivery of blood, oxygen, and nutrients to the fetus and 
clearance of fetal waste products including carbon dioxide and urea. The substrates for utero-placental transport are derived from maternal nutrient stores [11]. In early and mid-gestation, maternal food intake increases 10-15\%, intestinal calcium absorption doubles, and there is a $60 \%$ rise in first-phase insulin secretion. Because insulin sensitivity is preserved during the first half of pregnancy, the increase in insulin secretion promotes lipogenesis and limits fatty acid oxidation, facilitating maternal fat storage [12]. In midand late gestation, maternal food intake and fat mass escalate, but maternal metabolism is transformed by the emergence of insulin resistance. This facilitates maternal utilization of free fatty acids as an energy source, sparing glucose, amino acids, essential fatty acids, and ketones for placental-fetal transport and fetal growth [12].

Persistently high maternal blood glucose, as often observed in uncontrolled diabetes mellitus crosses the placenta from the maternal compartment to the fetal compartment and induces the release of insulin and insulin growth factors, which stimulates fetal growth [6]. This growth is especially marked in the clavicles and other shoulder bones. Apart from growth of bones, there is also deposition of adipose tissue, which increases the size and weight of the fetus [7]. The situation in diabetes mellitus is simulated in a pregnant woman who indulges in sugary beverages and foods containing highly refined sugars and fatty foods, such as are obtainable in fast food restaurants. The use of high energy drinks and food enhanced by high content of refined sugar and fat may enhance the development of excessive weight gain [13] in pregnancy and consequently fetal macrosomia.

\section{NUTRITIONAL HABITS}

In recent times, fast foods [14] and sugary beverages are fast replacing traditional feeding habits or becoming additional sources of nutrition. Pregnant women are not excluded but even pampered with these new fads. Women transiting from low income to higher income families through marriage are prone to overindulgence in sugary beverages and fast foods, which often contain highly refined sugar and unsaturated fats. (Personal observation) They are therefore prone to fetal macrosomic pregnancies.

In addition to fast food restaurants, which are becoming common in medically underserved areas, local nutritional habits and poverty, which encourage women including those who are pregnant, to eat cheap energy dense carbohydrate diets [15] with high glycemic index [16] in large quantities may also give rise to a situation where there is consistently high blood sugar commonly observed in persons with uncontrolled diabetes mellitus. One common carbohydrate diet in Southern Nigeria is cooked fermented cassava [16] variously called Akpu, fufu, Santana, or 'Six to Six'. It was named 'Six to Six' by low income laborers, who observed that a meal of cooked fermented cassava could sustain them at work from $6 a \mathrm{~m}$ to $6 \mathrm{pm}$. Such a meal, particularly when it is sold at less than 15 U.S cents per $750 \mathrm{~g}$ wrap, (personally measured average weight) portends danger of overindulgence in low income communities. Such is the case in many rural areas and with many urban poor. Pregnant women are not excluded from this overindulgence, especially in the second and third trimesters of pregnancy, when the appetite is good and fetal growth is rapid [7].

\section{COMPLICATIONS OF FETAL MACROSOMIA}

Diagnostic difficulties may occur due to several differentials which include hydramnios, $[17,18]$ multiple pregnancy, coexisting uterine fibroid and hydrops fetalis [19]. Complications may occur in all stages of labor, which may increase the rate of obstetric intervention.

During the first stage, progress may be slow resulting in a need for augmentation of labor. Cervical dystocia may occur due to cephalo-pelvic or feto-pelvic disproportion. In neglected cases, obstructed labor and sometimes ruptured uterus occur. Fetal weight monitoring, early induction of labor, and Cesarean section have therefore been suggested as a solution to the problem of fetal macrosomia [20]. However, routine induction of labor only increases the rate of cesarean sections [20].

In the second stage of Labor, delayed second stage and shoulder dystocia are common complications, which may result in vagina and perineal trauma, birth injuries and birth asphyxia. Post-partum hemorrhage may complicate the third stage of labor due to prolonged labor, oxytocin augmentation, vaginal and perineal trauma [5].

\section{MANAGEMENT OF FETAL MACROSOMIA}

Fetal macrosomia may be diagnosed by a clinical examination of the abdomen, noting especially the abdominal girth and the symphysio-fundal height measurements. Ultrasound scan may identify fetal 
macrosomia accurately but can only estimate fetal weight with decreasing precision as gestational age increases [1]. However, diagnosis of fetal macrosomia is mainly retrospective as the actual birth weight can only be measured after the delivery of the fetus.

Trial of labor is recommended in all cases of fetal macrosomia [1]. Some women are able to deliver a macrosomic baby under the supervision of an experienced obstetrician, who can manage the problems presented by shoulder dystocia, birth asphyxia or postpartum hemorrhage. However, some centers routinely carry out cesarean sections with the aim of preventing shoulder dystocia and its associated sequelae of brachial plexus injury. Some investigators have calculated that if cesarean delivery was performed in all instances in which birth weight was anticipated to exceed $4,500 \mathrm{~g}, 155$ to 588 cesareans would be required to prevent one permanent brachial plexus injury [21].

\section{MANAGEMENT OF FETAL MACROSOMIA MEDICALLY UNDERSERVED AREAS}

In medically underserved areas such as rural areas in developing countries, only primary health centers and maternities are usually available. Unfortunately, medically underserved areas are also the societies where ignorance, illiteracy and poverty are common. First and second phases of delay [22] are common and patients may not present to the midwife until very late in labor. Besides, the causes of fetal macrosomia such as uncontrolled diabetes mellitus, pre-gravid maternal obesity and gestational weight gain are associated with other health risks such as hypertension, heart problems and risk of thrombo-embolism [23]. The combined effect of the associated health risks and socio-cultural factors make its management particularly hazardous in medically underserved areas and are capable of increasing maternal mortality ratio thereby making the millenium development goal [V] unattainable by 2015 . Most of these deaths are due to preventable causes such as prolonged obstructed labor, ruptured uterus and post-partum hemorrhage. In certain parts of Nigeria, which are serviced by midwives working in the Midwives Service Scheme [24], terrorist bomb attacks, religious and cultural differences are hindering services meant to ameliorate the situation. The best option is to refer all cases of fetal macrosomia to district or tertiary hospitals known to have a functional obstetric unit. However, in many parts of the developing world, the primary health centers may not be adequately equipped in terms of personnel [25] who can make early diagnosis and, may be very far from adequately equipped obstetric units. It is therefore probably expedient to prevent the development of fetal macrosomia especially in medically underserved areas.

\section{PREVENTION OF FETAL MACROSOMIA}

Diabetes mellitus should preferably be diagnosed before the onset of pregnancy. Those not previously diagnosed will be identified during screening in the antenatal clinic. All women must therefore be educated on the compulsory need to attend antenatal clinics through word of mouth, electronic and print media. All pregnant diabetic patients should have their fasting blood sugar monitored and controlled throughout pregnancy; pre-pregnancy and first trimester for prevention of congenital malformations, in the second and third trimester for prevention of fetal macrosomia and shoulder dystocia.

Excessive gestational weight gain is associated with poor pregnancy outcome and increased intervention rate due to pregnancy complications such as fetal macrosomia, pregnancy induced hypertension and antepartum hemorrhage [26]. It has been suggested that minimal gestational weight gain might normalize birth weight and that prospective studies should be performed to clarify the safety of recommending limited gestational weight gain [27].

It has been suggested in a research carried out with pregnant Sprague Dawley rats that injection of a low dose of aqueous extract of Alligator pepper was capable of reducing gestational weight gain and litter size without affecting the morphologic, genetic or reproductive capability of the offsprings [28]. Further research is necessary to determine the feasibility of this or other food supplement or vaccine that can prevent fetal macrosomia in humans.

Dietary restriction during pregnancy might reduce weight gain but magnitude of dietary restriction that will reduce gestational weight gain to Institute of Medicine's accepted level of $9-12 \mathrm{~kg}$ [26] is difficult to estimate probably because of individualized metabolic rates. However, restricting diets to balanced diets without the use of sugary and alcoholic beverages may be capable of reducing gestational weight gain to the accepted institute of medicines range and improving the pregnancy outcome by lowering caesarean section rates, pregnancy induced hypertension and traumatic deliveries. There is a need to educate pregnant women 
on use of sugary and alcoholic beverages as well as energy dense carbohydrate diets.

\section{CONCLUSION}

Prenatal over-nutrition predisposes to fetal macrosomia, which is prone to complications and hazards during delivery. Fetal macrosomia may be prevented by dietary restriction during pregnancy. Information may be passed to women attending antenatal clinics during health education sessions to avoid sugary beverages and energy dense carbohydrate diets during pregnancy. Since there could be problems of non compliance due to increased appetite during pregnancy, there is a need for the development of food supplement or vaccine that can prevent fetal macrosomia. Research should be done to determine the active constituent of the aqueous extract of the seeds of Alligator pepper (Zingiberaceae Aframomum melegueta), which has been found to reduce gestational weight gain and litter size in Sprague Dawley rats, without altering the genetic, reproductive and morphologic characteristics of the offsprings.

\section{CONFLICTS OF INTEREST}

None declared.

\section{FUNDING}

None.

\section{ETHICAL APPROVAL}

Department of Research and Statistics of the Ministry of Health, Benin City, Edo State, Nigeria.

\section{REFERENCES}

[1] Resnik R. Fetal Macrosomia: 3 management Dilemmas. OBG Management 2003; 15(12): 28-36.

[2] Alexander GR, Himes JH, Kaufman RB, et al. A United States national reference for fetal growth. Obstet Gynecol 1996; 87: 163-68. http://dx.doi.org/10.1016/0029-7844(95)00386-X

[3] Cunningham FG, Leveno KL, Hauth JC, Gistrap LC, Wenstrom K. Fetal Growth Disorders. Williams Obstetrics. $22^{\text {nd }}$ ed. McGraw Hill 2005; pp. 893-907.

[4] Nicholson C. The Two Main Diameters at the Brim of the Female Pelvis. J Anat 1945; 79(Pt 3): 131-35.

[5] Zamorski MA, Biggs WS. Management of Suspected Fetal Macrosomia. Am Fam Physician 2001; 63(2): 302-307.

[6] Abudu OO, Awonuga AO. Fetal macrosomia and pregnancy outcome in Lagos 1989; 28(3): 257-62.

[7] Sacks DA. Etiology, detection, and management of fetal macrosomia in pregnancies complicated by diabetes

mellitus. Clinical Obstetrics and Gynecology. Lippincott Williams \& Wilkins 2007; 5(4): 980-989.

http://dx.doi.org/10.1097/GRF.0b013e31815a6242

[8]

[10] Hoffman DJ. Obesity in Developing Countries: Cause and Implications. Food Nutr Agric 2001; 28: 35-44.

[11] Freemark M. Regulation of maternal metabolism by pituitary and placental hormones: roles in fetal development and metabolic programming. Horm Res 2006; 65(Suppl 3): S41S49.

\section{http://dx.doi.org/10.1159/000091505}

[12] Freemark M. Placental hormones and the Control of Fetal Growth. J Clin Endocrinol Metab 2010; 95(5): 2054-57. http://dx.doi.org/10.1210/jc.2010-0517

[13] Hanlon P, Byers M, Walker BR, Slimmerton C. Environmental and Nutritional factors in disease. In: Boon NA, Colledge NR, Walker BR, Eds. Davidson's Principles and Practice of Medicine. $20^{\text {th }}$ ed. Churchill Livingstone Elsevier 93-125.

[14] Pereira MA, Kartashov Al, Ebbeling CB, et al. Fast-food habits, weight gain, and insulin resistance (the CARDIA study): 15-year prospective analysis. Lancet 2005 365(9453): 36-42. http://dx.doi.org/10.1016/S0140-6736(04)17663-0

[15] Hossain P, Kawar B, Nahas ME. Obesity and Diabetes in the Developing World - A Growing Challenge. N Engl J Med 2007; 356: 213-15.

http://dx.doi.org/10.1056/NEJMp068177

[16] Inediohanma, Determination of the Glycemic Indices of Three Different Cassava Granules (Garri) and the Effect of Fermentation Period on Their Glycemic Responses. Pak J Nutr 2011; 10(1): 6-9.

http://dx.doi.org/10.3923/pjn.2011.6.9

[17] Hoegsberg B, Gruppuso PA, Coustan DR. Hyperinsulinemia and macrosomic infants of non-diabetic mothers. Diabet Care 1993; 16: 32-36

http://dx.doi.org/10.2337/diacare.16.1.32

[18] Eberhard M. Fetal Growth Disturbances in the Second and Third Trimesters. Ultrasound in Obstetrics and Gynecology, $2^{\text {nd }}$ ed. Stuggart: Thieme 2005; 1: 175-178.

[19] Greenberg F, Stein F, Gresik MV, et al. The Periman Familial Nephroblastomastosis Syndrome. Am J Med Genet 1986; 24(1): 101-10.

http://dx.doi.org/10.1002/ajmg.1320240112

[20] Chauhan SP, Grobman WA, Gherman RA, et al. Suspicion and treatment of the macrosomic fetus: A review. Am J Obstet Gynecol 2005; 193: 332-46.

http://dx.doi.org/10.1016/j.ajog.2004.12.020

[21] Bryant DR, Leonardi MR, Landwehr JB, et al. Limited usefulness of fetal weight in predicting neonatal brachial plexus injury. Am J Obstet Gynecol 1998; 179(3 pt 1): 68689

http://dx.doi.org/10.1016/S0002-9378(98)70065-1

[22] Thaddeus S, Maine D. Too far to walk: maternal mortality in context. Soc Sci Med 1994; 38(8):1091-1110. http://dx.doi.org/10.1016/0277-9536(94)90226-7

[23] Ogunbode AM, Fatiregun AA, Ogunbode OO. Health Risks of Obesity. Ann Ibadan Postgraduate Med 2009; 7(2): 22-25.

[24] Abimbola S, Okoli U, Olubajo O, Abdullahi MJ, Pate MA. The Midwives Service Scheme in Nigeria. PloS Med 2012; 9(5). http://dx.doi.org/10.1371/journal.pmed.1001211 
[25] Inegbenebor $U$. Conceptual model for the prevention of maternal mortality in Nigeria. Tropical Doctor 2007; 2(37): 104-106. PMID: 17540095 http://dx.doi.org/10.1258/004947507780609202

[26] Abrams B, Altman SL, Pickett KE. Pregnancy weight gain: still controversial. Am J Clin Nutr 2000; 71(5): 1233S-41s.

[27] Jensen DM, Ovesen P, Beck-Nielsen $\mathrm{H}$, et al. Gesttional weightgain and pregnancy outcome in 481 obese glucose tolerant women. Diabet Care 2005; 28(9): 2118-22.

http://dx.doi.org/10.2337/diacare.28.9.2118
[28] Inegbenebor U, Ebomoyi MI, Onyia KA, Amadi K, Aigbiremolen AE. Effect of Alligator Pepper (Zingaberaciae Aframomum meligueta) on Gestational Weight Gain. In Nigerian J Physiol Sci 2009; 24(2): 165-69. PMID: 20234759

Received on 07-09-2012

Accepted on 05-10-2012

Published on 16-10-2012

DOI: http://dx.doi.org/10.6000/1929-5634.2012.01.01.10 